\title{
Dyonélio Machado como figura pública e intelectual brasileiro: notas para compreensão
}

\author{
Dyonélio Machado as a public figure and a brazilian intelectual: notes to a \\ comprehension
}

Jonas Kunzler Moreira Dornelles ${ }^{1}$

\section{Resumo}

O artigo visa apresentar aspectos da carreira intelectual do escritor, médico psicanalista, jornalista e político Dyonélio Machado. Partindo de sua trajetória biográfica, busca-se indicar suas principais contribuições para certas áreas do conhecimento. Destacado intelectual de seu tempo, ainda assim sua carreira acabou sofrendo devido a prisão política, ao boicote editorial, e quando eleito deputado, a cassação de mandato. O que fica evidente é a integridade do sujeito, que não admitia concessões, e que em todas áreas a que se dedicava, desenvolvia com seriedade seu trabalho intelectual. Com isso, busca-se contribuir para a respeitabilidade de sua figura, por vezes aviltada em sua trajetória.

Palavras-chave: Dyonélio Machado. História intelectual. Intelectuais brasileiros.

\begin{abstract}
The article aims to present aspects of the intellectual career of the writer, psychoanalyst, journalist and politician, Dyonélio Machado. Starting from his biographical trajectory, it aims to indicate the main points of his thought, as well as his contribution to certain fields and areas of knowledge. A prominent intellectual of his time, his career suffered through political arrest, editorial boycott, and when elected state deputy, the removal of office. What is evident is the integrity of the subject, who did not allow concessions, and who in all areas to which he devoted himself, developed his intellectual work seriously. With this, it tries to contribute to the respectability of his figure, sometimes outcasted in his career.
\end{abstract}

Keyword: Dyonélio Machado. Intelectual history. Brazilian intelectuals.

\footnotetext{
${ }^{1}$ Mestre em Letras - área de concentração Teoria, Crítica e Comparatismo pela mesma universidade UFRGS e Mestrando na linha de pesquisa Literatura, História e Memória - PPG-Letras PUCRS. Email: jkdornelles@hotmail.com
} 
Autor geralmente lembrado por sua produção literária, Dyonélio Machado atuou em diversos campos, realizando contribuições extra-literárias por vezes esquecidas nos relatos biográficos. Considerando o breve espaço de um artigo, iremos esboçar o caráter de sua persona pública, através de marcos biográficos e etapas de atuação, de maneira a se revisar sua imagem pública. Sua trajetória como médico psiquiatra e político atuante, serve de condutor para sua produção ensaística. Sujeito de certa maneira proscrito, a exposição desse panorama visa mostrar sua imensa respeitabilidade como profissional, artista e cidadão.

Considerado por muitos um dos maiores escritores do Rio Grande do Sul, nosso intelectual possui uma vida que por si só assemelha-se literatura. Nascido em Quaraí, cidade que faz fronteira com o Uruguai, vem ao mundo dois dias antes do fim da chamada Revolução Federalista. Era um recém nascido quando da assinatura de um tratado de paz de 1985, ao ponto que seus pais chegaram a se preocupar que os foguetes em comemoração pudessem furar seus tímpanos. Dyonélio crescerá ouvindo causos e histórias em rodas de chimarrão, testemunhando visitas de caudilhos remanescentes na região, que anos depois ainda permaneceria muito afetada pela disputa.

Com apenas sete anos, seu pai seria assassinado em um duelo, tendo sido morto à traição. O sujeito assassino desfere vários golpes com punhal em seu pai, que intencionalmente tinha ido desarmado para a batalha, numa atitude franca e idônea que Dyonélio procurará seguir em sua trajetória futura. Essa tragédia cria dificuldades para família sobreviver, o que levou o jovem muito cedo a ter de trabalhar para sustentar sua família. É vendendo tíquetes de loteria para sustentar a família que passaria por outro episódio trágico: acabará tendo de vender um bilhete para o assassino de seu pai. "Não queiram passar pelo momento que eu passei, negociar com quem me tornara órfão" (TILL, 1995, p.22). Nessa idade trabalha ainda como balconista e dando reforço escolar para colegas das séries menores.

Ainda que seu núcleo familiar estivesse empobrecido, Dyonélio cresce em um ambiente onde o debate intelectual era muito presente. Um parente seu teria sido prefeito de Quaraí, e outro foi diretor de escola, livreiro, jornalista fundador de um semanário local, além de homem envolvido com teatro. O senador Francisco Flores da Cunha, irmão do futuro governador do Estado, era próximo de 
sua família, sendo padrinho de seu pai. Crescendo cercado de livros e jornais, Dyonélio teria a oportunidade de estudar com Aurélio Afonso Porto, historiador de importância que posteriormente se mudaria para o Rio de Janeiro, onde publicaria obras que registram episódios relevantes sobre a História do povo gaúcho.

Em uma cidade do interior como Quaraí, que na época possuía cerca de três mil habitantes, foram oportunidades únicas para sua formação intelectual. Iniciase nos clássicos (Balzac, Eça de Queiroz, João do Rio, Machado de Assis, etc) devorando livros na biblioteca do Clube Comercial de Quaraí. Ainda na cidade, ganhará experiência trabalhando jornal $O$ Quaraí, o que lhe permite muito jovem a participar da fundação de outro, O Martelo.

Já adolescente, muda-se para Porto Alegre em 1912, para estudar preparatórios para o ingresso no curso de medicina. É nessa época que consolida alguns de seus conhecimentos, estudando latim com Afonso Emílio Meyer, figura pública conhecidíssima àquela época, tio do futuro poeta e crítico Augusto Meyer. Ainda que fosse conhecido por sua severidade, Dyonélio lembraria que foi "O maior professor que eu já conheci”.

Dividindo a moradia com colegas e outros estudantes do interior, acabará formando um grupo informal de artistas e jornalistas, que fica conhecido como "República do Império”. Participam desse grupo escritores importantes como De Sousa Júnior e Alceu Wamosy, além de figuras intelectuais como Celestino Prunes e Francisco Bellanca. O grupo se forma dentro de um contexto de recepção do Naturalismo e do Simbolismo no Rio Grande do Sul, sendo uma geração mais nova que o grupo do poeta Eduardo Guimarães, e uma geração mais velha que o grupo da "República da Olaria”, da qual participaria Aureliano de Figueiredo Pinto.

Os jovens da“República do Império” se reuniam na Confeitaria Schramm, na Rua dos Andradas, e sempre que possível iam ao ainda rudimentar Parque Harmonia, para realizarem seus serões. Juntos iam a óperas, treinavam-se na gramática, compartilhavam as novidades literárias e serviam-se de público para suas primeiras produções. Foi um período de sonhos e ideais, ainda que sob a trevas da Primeira Guerra, no qual Dyonélio acaba consolidando sua formação literária e seu estilo pessoal. Nessa época, escreverá crônicas sobre acontecimentos da época para a Gazeta de Alegrete, e para a revista Máscara. 
Sem conseguir terminar o preparatório para medicina, volta para Quaraí, por volta de 1916, tornando-se diretor e professor de um colégio municipal, onde sua futura esposa também lecionava. Inicia assim seu relacionamento com a professora de música Adalgiza, com quem casaria alguns anos depois. Atuaria também em uma das secretarias do município, sendo um braço direito do prefeito à época. Retornaria definitivamente para Porto Alegre por volta de 1920, quando passa no concurso para Secretaria de Obras Públicas, tornando-se secretário de Almoxarifado do Estado sob governo de Borges de Medeiros. Instalando-se por aqui, será membro da Associação de Imprensa, chegando a presidente da instituição.

Com isso, Dyonélio Machado vai se aproximando dos grupos republicanos e positivistas, com quem já possuia ligações familiares. Chegando a ser emissário e homem de confiança do governador, levando uma carta e participando de uma reunião com autoridades máximas da federação no Rio de Janeiro (o que chega a servir de material para seu primeiro romance, escrito em 1926, O Estadista). Em 1922, um ano antes da Revolução de 1923, funda e dirige A Informação, junto com seu antigo amigo, De Sousa Júnior. A publicação se destaca por seus ataques contundentes ao presidente Epitácio Pessoa e seu sucessor, Arthur Bernardes. O periódico é tão severo em suas denúncias, que na edição comemorativa do primeiro aniversário, o governador e aliado Borges de Medeiros decide pelo fechamento do jornal. Dyonélio fundará então o Farrapo, que durará oito números, indo até o auge da agitação de 1923, quando também é encerrado.

O corolário desse período é a publicação de seu primeiro livro ensaístico, a obra Política Contemporânea - Três aspectos (MACHADO, 2016). Nos artigos que compõe o livro, Dyonélio mostra mostrará uma avançada compreensão teórica de questões econômicas, sociológicas e políticas, desenvolvidas no contato com os grupos positivistas do Partido Republicano do Riograndense (PRR).

No primeiro dos três textos, apresentará uma análise de conjuntura do Brasil no pós-guerra, levantando considerações sobre os desafios a serem enfrentados no momento. Acabado os problemas gerados pelo conflito, surgia um problema muito maior: o "Problema da Paz", "mais assustadora que a própria guerra" (MACHADO, 2016, p.19), dado que exigia uma solução complexa para os múltiplos desafios que se apresentam. Dyonélio divide em questão social, questão 
internacional e questões nacionais, cada uma com suas próprias contingências. O desafio é sobretudo econômico, e sobram críticas às políticas adotadas por Epitácio Pessoa. Nosso pensador se autoproclama "modesto soldado republicano", e chega a sugerir uma espécie de reforma agrária como solução produtiva, mas crê não ser viável naquele momento. Mais adiante indica a solução de uma reforma tributária, com taxação justa de rendas, como um velho sonho do PRR (MACHADO, 2016, p.32).

No próximo artigo, será levantada a questão militar brasileira. Reconhecendo o crescimento do poderio norte-americano, e percebendo de imediato sua estratégia de avanço sobre os países latino-americanos sob justificativa de ameaça bélica, Dyonélio (talvez sob influência de debates que ocorriam na Liga das Nações) sugere o desarmamento geral da nação, na busca de tornar-se um exemplo, e afastar assim possíveis invasões ianques sob esse argumento. Aplaude ainda iniciativas da Argentina e do Chile em prol de um panamericanismo.

O último dos aspectos tratado no livro serão os movimentos revolucionários, e é interessante que uma “teoria da Revolução” em Dyonélio surja quando ele ainda fazia parte do partido de Borges de Medeiros, e não quando já convertido ao marxismo. Faz isso resgatando as origens da república moderna na Revolução Francesa, e o contexto que daria origem a Revolução de 1923, a partir da perseguição política da República Velha aos militares tenentistas. É partindo disso que fará uma "análise sociológica da revolução".

Iniciada em contexto de crise com atos de desobediência, depende de um sentimento de revolta generalizado e de uma oportunidade, se deflagrando numa situação propícia. Sem essas condições, o movimento pode não ganhar repercussão, e ser visto como um crime comum. Caso reverbere na população, seu sucesso dependerá enfim das operações militares. Considera-se um "partido revolucionário" o grupo de pessoas que se forma em parte espontaneamente, e não possui líderes ou chefes por mera ascendência partidária, mas trabalha em seu próprio seio por uma seleção intuitiva de seus porta-vozes. Todos são tributários, somam-se todas as queixas e ressentimentos, e durante seu ataque, por vezes forças perversas acabam operando, mas espera-se que seu manancial seja puro. 
O livro conclui com uma análise sobre a revolta do Forte de Copacabana, não chegando a comentar a Revolução que ocorreria no ano seguinte. Durante o conflito, que tem suas ocorrências regionais Dyonélio trocará correspondências com corregionários do PRR por todo Estado, buscando informações sobre forças oposicionistas em composição. Para combatê-las, os Borgistas criariam a Guarda Republicana, na qual se voluntariavam centenas de correligionários.

Não temos maiores pormenores sobre sua atuação em 1923, além de sua militância jornalística e participação em grupos muitos próximos de Borges de Medeiros. No ano seguinte, à pedido da esposa, retorna a seu plano de ingressar no curso de medicina. Com o trabalho lhe permitindo estudar apenas à noite e nos fins de semana, sua primeira filha recém nascida, e se matriculando no curso preparatório com meses de atraso, mesmo assim o escritor passaria com distinção nos exames de latim, um do três preparatórios que lhe faltavam.

Cursará faculdade entre os anos 1924 e 1929 e já próximo da conclusão, prestaria concurso para médico do Hospital São Pedro, passando em primeiro lugar e conquistando a nomeação. É por volta dessa época que conclui seu primeiro livro de contos Um pobre homem, e o romance que deixará inédito, $O$ Estadista. Terminada a formação clínica, decide especializar-se no Rio de Janeiro, concluindo seu doutorado em psiquiatria em 1932. "Na época que me formei, em 1929, no Brasil, no Rio Grande do Sul, éramos apenas dois ou três psiquiatras. Havia clientela, não havia mãos a medir. Houve um fator que concorreu para isso: a introdução da psicanálise, empolgando as pessoas” (MACHADO, 1995, p. 10).

Essa especialização oferece uma rara oportunidade, algo pioneira em uma época em que a universidade brasileira ainda dava seus primeiros passos. Dessa época, ficou o testemunho das publicações do Arquivos brasileiros de neuriatria e psiquiatria (1931), onde se reconhece sua atuação como auxiliar dos grandes cientistas, que realizavam procedimentos experimentais na Sociedade Brasileira de Neurologia, Psiquiatria e Medicina Legal, considerada a primeira sociedade brasileira especialista em medicina mental (CERQUEIRA, 2016)

Após a defesa de sua tese, Dyonélio a publicaria pela Editora do Globo, sob o título de Uma definição biológica do crime (1933). Nela analisará a questão do crime (em especial do homicídio) não pelo viés do Direito, mas considerando as relações existente entre biologia, psicologia e o modo de organização da sociedade. 
A obra faz uma análise antropológica do crime, reconhecendo que é na busca de realização de suas necessidades humanas (abrigo, alimentação, relações sexuais) que o ser humano incorre na delinquência, quando age de maneira desmedida. " $O$ delito, em particular o assassínio, nada mais é do que a resultante, contra o semelhante, do excesso que o homem põe na realização da luta pela vida”. (MACHADO, 1933, p. 22).

Dyonélio inicia a obra distinguindo o crime entre animais, e fazendo um resgate da questão em povos primitivos. É o surgimento da punição que se poderia demarcar uma linha divisória entre ambos. Citando Freud, comenta que é com o advento cultural dos tabus, que internalizam as leis, que um longo processo histórico fez o crime passar de regra à exceção, até a sociedade humana se organizar na forma recente da instituição do Direito. Passando do plano natural ao plano da psicologia, pode-se identificar a influência individual, definindo-se analiticamente aquilo que será caracterologia da psicologia do delinquente, ao reconhecer o temperamento criminal como exageradamente autocentrado. São esses aspectos de personalidade que levariam a percepção de uma ameaça a sua autopreservação, que não existiria objetivamente, apenas subjetivamente. Isso levará o autor a sugerir uma revisão da questão da "responsabilidade penal" no campo da criminologia, questão que as conclusões de seu trabalho apenas deixam abertas para futuras análises.

Retornando para Porto Alegre, publicaria ainda a tradução de Elementos de Psicanálise, de Eduardo Weiss, pela Editora do Globo (1934). Essa obra, com breve introdução do próprio Sigmund Freud, seria uma das responsáveis por introduzir a psicanálise no Estado. Sendo um compêndio escrito já sob a incorporação das descobertas de Além do princípio do Prazer, seu texto continua sendo uma ótima apresentação dos vocabulário e diagnósticos freudianos. Dyonélio viria a ser um dos pioneiros na aplicação de tais técnicas terapêuticas, quando de sua atuação como médico do Hospital São Pedro.

A ascensão de Getúlio Vargas à política nacional, com a revolução de 1930, vai mudando pouco a pouco o cenário de atuação política. Retira o poder das autoridades regionais, instaura uma nova constituição brasileira, reconfigurando as peças no jogo de poder e as estratégias possíveis. Muitas lideranças gaúchas que o apoiaram julgam-se traídas. Será mais ou menos nesse contexto que dois 
8 | Opinião Filosófica, V. 10, n. 2, 2019 - Brasil Filosófico e seus pensadores

acontecimentos marcantes na vida de Dyonélio acontecem. A primeira é a escrita de Os Ratos (1935), seu primeiro romance publicado. Esgotado rapidamente em sua primeira edição, ganhará o prêmio Machado de Assis, que lhe dá uma projeção literária com renome nacional. A outra será sua prisão como presidente regional da Aliança Nacional Libertadora (ANL), o que ocorrerá quase simultaneamente ao sucesso do livro.

Tanto o comunismo quanto o integralismo vinham ganhando força no cenário brasileiro. É rejeitando o último que nosso pensador se aproxima de Luís Carlos Prestes. Em suas memórias, Dyonélio compara o surgimento da organização com as Frentes Populares européias, e com o movimento político que futuramente levaria Salvador Allende ao poder no Chile, buscando mostrar sua legitimidade em outros cenários. Ainda não havia assumido o marxismo como posicionamento, mas já se situava à esquerda.

A inauguração pública da organização mostra como as estratégias contemporâneas de fake news são antigas. Uma campanha de difamação e ameaças inicia-se semanas antes do ato solene que ocorreria no Teatro São Pedro. Prevendo uma tragédia, Dyonélio instrui todos a manterem a calma e irem desarmados. O chefe de polícia e quase uma dezena de delegados comparecem no ato, e provocadores se infiltram entre o público, buscando iniciar uma confusão que atrapalhasse o evento e pudesse levar à prisão de seus líderes. Apesar disso tudo, a inauguração é um sucesso, e tudo acaba num ambiente ordeiro. No dia seguinte, 6 de julho de 1935, é publicado no Correio do Povo uma notícia caluniosa, que receberá resposta do escritor, no mesmo jornal, na edição de 9 de julho, oferecendo sua perspectiva testemunhal dos fatos.

Menos de dez dias depois, Getúlio Vargas irá ordenar o fechamento da ANL em nível nacional. Descontentes com o arbítrio, os integrantes gaúchos decidem organizar uma greve, e no processo de divulgação do ato político, Dyonélio Machado será detido, permanecendo encarcerado por cerca de oito meses. A prisão ocorre de maneira suspeita, sendo recolhido quando chegava de casa de madrugada, com os policiais o insultando e ameaçando. Assumirá as acusações de seus colegas, sendo preso no lugar de um deles.

Em resposta a prisão, o Sindicato de Médicos organiza-se um comitê em prol da liberdade de Dyonélio, que fará pressão até que ele receba um habeas 
corpus (A MANHÃ, 1935, p.6). O governador do Rio Grande do Sul nesse período é Flores da Cunha, antiga liderança republicana e irmão do padrinho de seu pai. O mesmo pronuncia-se dizendo que não vai haver concessões para agentes políticos como o líder da ANL. A oposição denúncia a "lei monstro", e após muita pressão, Dyonélio é libertado (A GAZETA, 1935, p.1).

No entanto, pouco tempo depois estoura a Intentona Comunista em nível nacional, o que gerou uma resposta sob forma de repressão violenta por parte do governo getulista, através da Lei de Segurança Nacional. Era a véspera do Estado Novo, e o escritor chega a brincar que deve ter inaugurado a nova legislação repressiva, pois o fato é que seria preso imediatamente a sua publicação. Mesmo não tendo participado do movimento, seria levado às prisões do Rio de Janeiro, onde amargaria dois anos sob o cárcere.

Ficará detido na Casa de Detenção, onde conhecerá outros intelectuais aprisionados, como Graciliano Ramos, e no processo, se converte ao comunismo. Na prisão sofrerá com as más condições, chegando a perder os dentes. Suas memórias desse período depois seriam convertidas em matéria para dois ciclos de romances seus, totalizando sete romances que tratarão do tema da perseguição, encarceramento e readaptação posterior à vida na sociedade.

Sua libertação se dará junto com outras 300 pessoas que haviam sido presos sem julgamento, num ato do ministro da justiça Macedo Soares, que ficaria conhecido como a "Macedada". Em parte foram denúncias de deputados, que na tribuna publicamente criticavam a situação das prisões do período. A qualidade do caráter de um "detento como Dyonélio" chega a ser exemplo de como as prisões eram injustas e arbitrárias (JORNAL DA MANHÃ, 1937, p.4), e quando da visita do ministro para inspecionar as condições do cárcere, será o próprio que o irá receber, para apresentar o estado deplorável do chamado "cemitério dos vivos" (JORNAL DO BRASIL, 1937, p. 11). Ajudará ainda a escrever um relatório, que levaria a concretizar o gesto de libertação que levaria o nome do ministro (DIÁRIO DE PERNAMBUCO, 1937, p.1).

De volta a Porto Alegre, permanece o risco de nova detenção. Volta para Quaraí, onde teria dificuldades de adaptar-se por conta do estigma político. Com a implementação do Estado Novo, teme por sua liberdade, fugindo para Santa Catarina disfarçado. Apenas meses depois, com o afastamento de Flores da Cunha 
do cargo de interventor do Estado, é que receberia anistia. Primeiramente atuando em um consultório na Galeria Chaves, será reintegrado no cargo do Hospital São Pedro, sendo homenageado em uma cerimônia de destaque. Participaria ainda como conferencista do $1^{\circ}$ Congresso de Criminologia, onde faz discussões sobre o tema recente da punição por contágio venéreo.

Apesar de tudo, pode-se perceber que nesse período sua figura gozava de grande e merecido prestígio, dentre os círculos intelectuais. Temos na entrevista publicada na Revista do Globo de 27 de janeiro de 1940 (MARTINS, 1940), a evidência indicativa desse clima, onde muitos ansiavam por notícias e um novo romance do escritor. Esse romance viria dois anos depois, e seria O Louco do Cati, um livro único, não escrito mas narrado da cama, tão revolucionário que a crítica do momento não soube bem como reconhecê-lo.

O livro se esgota, mas seria analisado negativamente pela crítica regional conservadora, nomeadamente Moisés Vellinho, e também brasileira. Pelo mesmo Álvaro Lins que também não saberia reconhecer uma autora como Clarice Lispector. Tal desajuste se agravaria com as próximas obras, levando-o a ter de publicar seus próximos livros fora de seu Estado. Seu Desolação (1944), que lhe garantiria o prêmio Felipe d'Oliveira pelo conjunto da obra, sairia por uma editora carioca. Traduzia um conto, e teria um texto de seu Um pobre Homem publicado, o que levaria a outro episódio de detenção, que no entanto dura apenas uma noite. Era o final da Segunda Guerra Mundial, e os militares não gostariam de ler sua denúncia da atuação histórica dos militares brasileiros na Guerra do Paraguai, de sua narrativa "Noite no Acampamento".

Como cientista, vinha pesquisando no campo da neurociência, investigando os potenciais cerebrais bioelétricos e o metabolismo da glicose no cérebro. Em 1944, fez uma viagem a Buenos Aires, onde estudou a aplicação do eletroencefalograma na avaliação das consequências dos tratamentos de choque. Faz uma apurada revisão bibliográfica sobre os efeitos não desejados dos tratamentos biológicos no sistema nervoso central e sobre as bases biológicas dos transtornos mentais, que culminaria no relatório Eletroencefalografia (1944), um tipo de pesquisa também inovador, que se desenvolveria no campo de tratamentos por via de drogas antipsicóticas e antidepressivas. 
Em 1945 será o representante regional do I Congresso Brasileiro de Escritores, atuando de maneira representativa nos trabalhos do evento e recebendo reconhecimento dos maiores escritores da geração. Conhecerá pessoalmente Mário de Andrade, Aníbal Machado, Tristão de Athaíde, entre tantos. Esse evento seria lembrado como um dos responsáveis por furar a censura e catalisar o fim do Estado Novo, tem Dyonélio em suas linhas de frente, sendo um dos autores do Manifesto, texto que defenderá a liberdade política e de pensamento. Com sua voz grave e treinada na oratória, faz seu pronunciamento que causará comoção no conjunto de ilustres ouvintes ali presentes. Posteriormente, viria a integrar também a União de Trabalhadores Intelectuais, organizada pelos escritores e jornalistas do período, e que continuaria a denunciar a censura política e a defender dos abusos os intelectuais ameaçados, participando da campanha de anistia que viria a ocorrer.

Publicará ainda seu romance Passos Perdidos (1946), por uma editora paulista. Nessa época, fundaria também o periódico Tribuna Gaúcha, junto com Décio Freitas. É nesse período que ocorrerá sua eleição como deputado estadual, pelo Partido Comunista Brasileiro. Eleito em 1947, terá uma breve mas intensa atuação. Será um dos deputados mais participativos, ocupando-se de debates sobre a produção agrícola, tributação das terras, as condições de trabalho dos operários, do Plano Rodoviário do Estado, as políticas de saúde mental, onde contribui com testemunho direto sobre as condições de internação de dependentes químicos no Hospital São Pedro. Divide a tribuna com figuras importantes, como Leonel Brizola e João Goulart, e será um dos deputados da Constituinte de 1947. Para esta, dará uma contribuição significativa a respeito da questão econômica e sanitária da alimentação no Rio Grande do Sul.

A atuação da pequena bancada de deputados comunistas era embasada e apaixonada, mas sempre muito cordial com colegas de outros partidos. Eram tempos delicados, e pode se dar um exemplo de como Dyonélio buscava alianças com outros setores. Quando da campanha de Alberto Pasqualini para governador, nosso escritor comenta com membros da bancada trabalhista do PTB que seria possível que o PCB apoiasse sua candidatura, sugestão que acaba sendo publicada nos jornais, e que seria publicamente corrigida por seus colegas (O JORNAL, 1947, 
p.3). O que indica que a atuação política de Dyonélio era tudo, menos pautada por dogmatismos, nem conduzida por superiores.

Com o fim da Segunda Guerra, a política nacional se reconfigurava. Getúlio Vargas deposto, cai junto o regime do Estado Novo. Encerrada a ditadura, surgem esperanças democráticas, com a eleição de Eurico Gaspar Dutra e a promulgação de uma nova constituinte. Formalmente se havia dado fim aos mecanismos de perseguição e censura, garantindo-se restauração de direitos e possibilidade de eleições com voto secreto. Mas no que diz respeito aos movimentos populares e trabalhistas, as perseguições continuaram, com o governo adotando medidas repressivas contra formação de sindicatos, intervindo em todos os níveis da estrutura sindical.

É nesse contexto que o presidente eleito irá colocar na ilegalidade o PCB, dissolvendo o partido em todos níveis, o que levará a cassação do mandato de Dyonélio Machado no início de 1948. Será um dos momentos mais amargos de sua trajetória, contados em suas Memórias de um pobre homem (MACHADO, 1995, p. 131-139), já que ele e seus colegas decidem resistir, mas não encontram reação popular que lhes apóie. Em reportagem publicada por Rubens Vidal em 19 de agosto 1950 na Revista do Globo, intitulada "Que fizeram vossas excelências?", relata-se o cotidiano da Assembléia naqueles dias, revelando como eram vistos os membros da bancada comunista por seus colegas. Terminada a votação que cassaria a bancada do PCB, o parlamentar Assumpção Viana, do PTB, declara: "Acabamos de expulsar os deputados mais eficientes dessa casa!" (VIDAL, 1950, p.64).

O golpe foi duro demais para o escritor, e a partir de então se afasta da política partidária. Um fato ainda aconteceria, quando da promulgação da Constituinte de 1947. Seria feito um quadro em homenagem aos membros do colegiado que redigiram seu texto, contendo a fotos de todos os deputados constituintes. O colegas do PCB entram em contato com Dyonélio, para pedir-lhe um retrato para o quadro, o que ele recusará, acusando-os de retroceder a um grupo que não lhe apoiou quando necessário. $\mathrm{O}$ resultado é que sua foto foi negada, e até hoje esse quadro, que pode ser visto exposto na Assembléia Legislativa, possui um vazio em um dos seus deputados retratados. 
A partir desse período, Dyonélio se dedicará a sua atuação no Hospital São Pedro, onde chegará a ser diretor da instituição em 1956. Viajará ao Rio de Janeiro para conseguir verbas para reformas na instituição, efetivamente realizando melhorias e inaugurando novos pavilhões. Será também responsável por desenvolver uma atuação mais humanitária aos pacientes e internos, com aplicação de técnicas terapêuticas não farmacológicas.

Há nesse momento um progressivo afastamento de Dyonélio da esfera literária. Não deixa de escrever romances, mas esses só serão publicados a partir da década de 1970, quando haverá uma espécie de redescoberta de sua obra, estando ele já está aposentado das atividades profissionais. É nessa época que dedica-se a escrever alguns ensaios, que constarão em jornais e revistas, todos recheados de sabedoria filosófica, e escritos com certa ironia de quem vinha dedicando-se aos grandes monumentos da cultura ocidental, situando sempre seu pensamento em pontos aporéticos ou paradoxais. Alguns exemplos encontram-se em Cheiro de coisa viva (MACHADO, 1995) ou nas entrevistas de Com a palavra, Dyonélio (AGUIAR et al., 2014).

A partir desse período, também se dedicará com maior regularidade à correspondência pessoal, chegando a servir de consultor para publicações como Alceu Wamosy - sua vida e obra (TILL, 1973), Coronel Dono do Mundo, de Luiz Luna e Nelson Barbalho (1983), e Comunistas Gaúchos de João Batista Marçal (1986). Sua biblioteca particular, nessa época era uma referência na América Latina, citada por um estudioso de bibliotecas particulares por sua reunir obras históricas, pacientemente reunidas para construção de seu ciclo de romances passados na Roma antiga (HOMEN, 1971, p.119).

Para concluir, vale destacar alguns dos atributos de Dyonélio ao final de sua vida: poliglota, dominava o francês, inglês, espanhol, grego e latim, além de italiano e um pouco de alemão. Tinha um conhecimento notável de História, Política, Psicanálise, Filosofia e Direito Romano, algo que se revela em suas memórias, onde com muita ironia articula Freud e Aristóteles, Marx e Platão. Desde muito jovem tinha lido o conjunto da obra de autores como Dostoiévski, Balzac, Flaubert, Eça de Queiroz, Machado de Assis, Charles Dickens, entre tantos. Como flautista, realizava serões em seu apartamento, onde acompanhado de sua esposa, amigos e familiares, executavam clássicos como Debussy, Satie e Chopin, 
além de composições clássicas de samba e tango. Arriscava também na escultura e na fotografia, além de hábil jogador de xadrez e truco.

Seus romances serviriam de amostragem para registros de palavras antigas, que seriam incluídas no dicionário Aurélio. Com isso passamos a sua obra literária, para dar alguns indicativos de suas qualidades. Um poeta e ensaísta de alto valor como Décio Pignatari colocaria Os Ratos acima de todos romances da geração de 30 (SIMÕES; LAFFE, 2007, p. E2), o que serve para indicar sua posição segura no cânone literário. Teríamos na protagonista de $O$ Louco do Cati a fusão do conceito de alienação marxista com sua concepção psicanalítica, feito poderoso bastante particular na História da Literatura. Seu Deuses Econômicos, que demorou dez anos para ser escrito, é bem sucedido em mimetizar o estilo da Antiguidade clássica de um Sêneca, recheado de humor romano mas ainda assim falando de temas atuais, como a ameaça política de facções religiosas, e os efeitos nocivos da repressão policial.

Essa obra nos fornece dois indicativos da genialidade de Dyonélio, e do sucesso da pesquisa que lhe custou dez anos para produzir tais livros. Nela será indicado que Jesus Cristo teria sido membro da seita dos Essênios, tese que só ganharia força décadas depois, com a descoberta e tradução dos textos conhecidos como Manuscritos do Mar Morto (LAPERROUSAZ, 1989), décadas depois. Além disso, ao relacionar concepções socialistas com o cristianismo primitivo, a obra antecipa em quase uma década o surgimento da Teologia da Libertação, atributo raramente relacionado a esse autor, que nesse ciclo de obras de certa maneira parece se aproximar dessas idéias.

A título de conclusão, fica a sugestão de leitura de suas Memórias de um pobre homem (MACHADO, 1995), um volume importante da memorialística brasileira, que resgata a trajetória de luta de um intelectual frente a repressão política e o boicote editorial. Mesmo que com todo seu sofrimento, buscou apresentar-se sem ressentimentos, ironizando muito mais a si mesmo do que seus opositores ou a situação política do país. Com isso, não evita a verdade de seu relato testemunhal, esperando que os fatos falem por si mesmo.

Para concluir, poderíamos aqui aproximar o caso de Dyonélio Machado, de uma personagem de que gostava muito, e a quem faz referências em suas memórias. Assim como Sócrates, nosso sujeito sofreu de uma lei injusta, a qual 
enfrentou de frente, sabendo que a posteridade saberia indicar qual dos lados estava equivocava. Sua figura então permanece na memória de nosso povo, servindo de modelo respeitável, que sabe divergir com honra frente os tempos incertos de ignorância e injustiça.

\section{Referências}

A CÂMARA dos deputados contra prorrogação do estado de guerra. Diário de Pernambuco. Recife. Ano 112, n. 178, p. 1, 10 jun 1937.

Archivos Brasileiros de Neuriatria e Psychiatria. Rio de Janeiro: Sociedade Brasileira de Neurologia, Psiquiatria e Medicina Legal, 1931.

AGUIAR, Vera Teixeira de; RAABE, Camilo Mattar; COLONETTI, Milton Roberto; PICCINI, Maurício da Silveira. Com a palavra, Dyonelio Machado. Porto Alegre: EDIPUCRS, 2014.

BARBOSA, Márcia Helena Saldanha; GRAWUNDER, Maria Zenilda. (Org.). Dyonelio Machado. Porto Alegre: Unidade Editorial Porto Alegre, 1995.

CERQUEIRA, Ede Conceição Bispo. A fundação da primeira sociedade brasileira especializada em medicina mental .Revista Brasileira de História da Ciência, Rio de Janeiro, v. 9, n. 1, p. 51-66, jan-jun 2016.

DORS, Marines. Dyonelio Machado (1895-1985): os múltiplos fios da trajetória ambivalente de um intelectual. 2008. 2008. Dissertação. (Mestrado em história). São Leopoldo: UNISINOS, 2008.

GAGLIETTI, Mauro José. Dyonélio Machado e Raul Pilla: médicos na política. Porto Alegre: EDIPUCRS, 2007.

GRAWUNDER, Maria Zenilda. A instituição literária: Análise da legitimação da obra de Dyonelio Machado. Porto Alegre: IEL: EDIPUCRS, 1997.

HOMEN, Homero. Grandes bibliotecas particulares. Revista de Cultura Brasileña. Madrid. n. 32, p.111-119, dez 1971.

KARLS, Cleber Eduardo. Quando o médico e o literato se encontram: as representações da loucura e do crime em Dyonélio Machado. 2008. Dissertação. (Mestrado em história). Porto Alegre: UFRGS, 2008.

LAPERROUSAZ, Ernest-Marie. Os manuscritos do Mar Morto. São Paulo: Círculo do livro, 1989.

LUNA, Luiz; BARBALHO, Nelson. Coronel dono do mundo: síntese histórica do coronelismo no Brasil. Rio de Janeiro: Cátedra; Brasília: INL, 1983. 
16 | Opinião Filosófica, V. 10, n. 2, 2019 - Brasil Filosófico e seus pensadores

MACHADO, Dyonélio. Deuses econômicos. Porto Alegre: Editora Garatuja, 1976.

MACHADO, Dyonélio. Endiabrados. São Paulo; Ática, 1980.

MACHADO, Dyonélio. Prodígios. São Paulo: Moderna, 1980.

MACHADO, Dyonélio. Nuanças. São Paulo: Moderna, 1981.

MACHADO, Dyonélio. Sol subterrâneo. São Paulo: Moderna, 1981.

MACHADO, Dyonélio. Ele vem do Fundão. São Paulo: Ática, 1982.

MACHADO, Dyonélio. Fada. São Paulo: Moderna, 1982.

MACHADO, Dyonélio. Passos perdidos. São Paulo: Editora Moderna, 1982.

MACHADO, Dyonélio. O cheiro de coisa viva. Rio de Janeiro: Graphia Editorial, 1995.

MACHADO, Dyonélio. Desolação. São Paulo: Editora Planeta do Brasil, 2005.

MACHADO, Dyonélio. O Louco do Cati. São Paulo: Editora Planeta do Brasil, 2003.

MACHADO, Dyonélio. Os Ratos. São Paulo: Editora Planeta do Brasil, 2004.

MACHADO, Dyonélio. O pensamento político de Dyonélio Machado. Porto Alegre: Assembleia Legislativa do Estado do Rio Grande do Sul, 2006.

MACHADO, Dyonélio. Proscritos. Brasília: Siglaviva, 2014.

MACHADO, Dyonélio. Um pobre homem. Brasília: Siglaviva, 2017.

MADRUGA, Artur. Dyonelio Machado. Porto Alegre: Tchê, 1986.

MARÇAL, João Batista. Comunistas gaúchos: a vida de 31 militantes da classe operária. Porto Alegre: Tchê!, 1986.

MARTINS, Justino. Dyonélio Machado quebra seu silêncio. Revista do Globo. Porto Alegre. p. 44-58, 27 jan. 1940.

O SR. ALBERTO Pasqualini aceitaria o apoio dos comunistas. O Jornal. Rio de Janeiro. Ano 29, n. 8259, p.3, 3 abr 1947.

OS MÉDICOS querem a liberdade do Sr. Dyonéllio Machado. A Manhã. Rio de Janeiro. Ano 1, n. 152, p.6, 18 out 1935.

PERMANECE agitada a situação nacional. A Gazeta. Florianópolis. n. 273, p.1, 20 jul 1935 . 
PODER legislativo. Correio da manhã. Rio de Janeiro. p. 4, 4 abr 1937.

SIMÕES, Eduardo; JAFFE, Noemi. Oitentação. Folha de São Paulo. São Paulo. p. E1-E3, 04 ago 2007.

TILL,. Rodrigues. Alceu Wamosy: vida e obra. Porto Alegre: Edições Flama, 1973.

TILL, Rodrigues. Dyonelio Machado: o homem, a obra. Porto Alegre: E.R.T., 1995 .

VIDAL, Rubens. Que fizeram vossas excelências?. Revista do Globo. Porto Alegre. n. 514, p. 23-64, ago 1950 .

VISITA do Sr. Ministro da Justiça às casas de detenção e correção. Jornal do Brasil. Rio de Janeiro. Ano 47, n. 132, p.11, 8 jun 1937.

WEISS, Eduardo. Elementos de psicanálise. Porto Alegre: Edições Globo, 1933.

Recebido em: 18/11/2019.

Aprovado em: 28/11/2019. 